PATTINGALLOANG

(CJurnal Pemikiran Pendidikan dan Penelitian Kesejarahan

\title{
Modernisasi Masyarakat Nelayan Kecamatan Pulau Sembilan Kabupaten Sinjai, 1960 - 2018
}

\author{
Haerul Akmal ${ }^{1}$, Patahuddin ${ }^{2}$, Bahri $^{3}$ \\ Program Studi Pendidikan Sejarah Fakultas Ilmu Sosial UNM \\ ${ }^{1}$ haerulakmal15@gmail.com
}

\begin{abstract}
Abstrak
Penelitian dan penulisan skripsi ini bertujuan untuk mendeskripsikan latar belakang kehidupan sosial ekonomi masyarakat nelayan, menguraikan kondisi kehidupan sosial ekonomi masyarakat nelayan di Kecamatan Pulau Sembilan sebelum dan sesudah modernisasi. Penelitian ini menggunakan pendekatan ilmu sejarah, sehingga tahap penelitian yang dilakukan adalah (1) Heuristik atau pengumpulan data, (2) Kritik (3) Interprtasi dan (4) Historiografi. Hasil penelitian menunjukkan bahwa karakteristik, pola hubungan kerja dan interaksi masyarakat antar pulau adalah bagian yang sangat penting dalam kehidupan sosial ekonomi masyarakat nelayan di kecamatan pulau sembilan. Sebelum masuknya pengaruh modernisasi, kehidupan nelayan tradisional di Kecamatan Pulau Sembilan memiliki banyak keterbatasan baik dari segi alat tangkap yang masih sangat sederhana begitupun dengan daerah jangkauan penangkapan yang masih terbatas. Alat tangkap yang digunakan berupa pancing, panah, bubuh,bagang tancap dan bagang rakit dengan orientasi penangkapan yang masih bersifat subsisten. Kondisi seperti ini mulai berubah ketika nelayan mulai mengenal modernisasi pada tahun 1970 yang di tandai dengan pengunaan mesin sebagai alat penggerak perahu yang pada akhirnya menyebabkan daerah jangkauan penangkapan menjadi lebih luas. Pengaruh modernisasi telah mengubah pola pikir masyarakat nelayan di Kecamatan Pulau Sembilan untuk beralih mejadi nelayan pembudidaya rumput laut. Peralihan ini memberikan dampak yang sangat besar terhadap kehidupan sosial ekonomi nelayan, yang ditandai dengan perubahan orientasi ekonomi dari subsiten menjadi komersil.
\end{abstract}

\section{Kata Kunci : Nelayan, Pulau Sembilan, Modernisasi}

\begin{abstract}
The research and writing of this thesis aims to describe the background of the socio-economic life of the fishing community, describing the socio-economic living conditions of the fishing communities in Pulau Sembilan District before and after modernization. . This study uses a historical science approach, so the stages of research carried out are (1) Heuristics or data collection, (2) Criticism (3) Interpretation and (4) Historiography. The results showed that the characteristics, patterns of work relationships and community interaction between islands are a very important part in the socio-economic life of fishing communities in Pulau Nine sub-district. Before the influx of modernization, the life of traditional fishermen in Pulau Sembilan Subdistrict had many limitations both in terms of fishing gear which was still very simple as well as the limited fishing range. Fishing gear that is used in the form of fishing rods, arrows, bubuh, stepang and stepang raft with a fishing orientation that is still subsistence. Conditions like this began to change when fishermen began to recognize modernization in 1970 which was marked by the use of engines as a means of driving a boat which ultimately led to a wider catchment area. The influence of modernization has changed the mindset of the fishing community in Pulau Sembilan Sub-
\end{abstract}


PATTINGALLOANG

(C) Jurnal Pemikiran Pendidikan dan Penelitian Kesejarahan

district to turn into seaweed cultivating fishermen. This transition has a very big impact on the socio-economic life of fishermen, which is marked by a change in economic orientation from subsistence to commercial

Keywords: Fisherman, Pulau Sembilan, Modernization

\section{A. Pendahuluan}

Negara Indonesia dibentuk secara bersama-sama oleh tiga laut inti yaitu Laut Jawa, Laut Flores, dan Laut Banda. Ketiga kawasan laut tersebut berperan sebagai heartsea dalam sejarah Indonesia (Hamid A. R., 2015). Salah satu pulau yang menjadi daerah maritim di Kawasan Indonesia Bagian Timur ialah Pulau Sulawesi khususnya di Sulawesi Selatan. Letak Sulawesi Selatan yang dikelilingi oleh wilayah lautan sehingga masyarakatnya banyak memilih profesi sebagai nelayan, terutama dalam usaha penangkapan ikan. Kegiatan kehidupan masyarakat sehari-hari, tampak telah akrab dengan suasana laut baik di wilayah pesisir pantai maupun di lepas pantai. (Ahmadin, 2017), Karena laut merupakan tempat untuk mencari nafkah bagi seorang nelayan dan merupakan aktivitas yang biasa mereka lakukan. (Alimuddin, 2004), Adapun salah satu daerah di Sulawesi Selatan yang hampir seluruh masyarakatnya menggantungkan hidupnya pada hasil laut dengan cara bekerja sebagai nelayan yaitu masyarakat yang ada di Kecamatan Pulau Sembilan Kabupaten Sinjai. Hal ini disebabkan oleh bentang alam daerah ini yang berupa gugusan pulau yang berjumlah sembilan.Nama-nama Sembilan Pulau tersebut yaitu, Burungloe (Pulau terbesar), Batang Lampe (pulau terpanjang), Larea-rea (pulau terkecil), Kambuno (ibu kota kecamatan), Kanalo 1, Kanalo 2, Liang-liang, dan Kodingare.Adanya proses kehidupan yang terjadi di Pulau Sembilan sangat erat kaitannya dengan kedatangan Suku Bajo dan Suku Bugis ke pulau ini. (BPS, 2018).

Sebagai suku pertama yang datang ke pulau ini, Suku Bajo awalnya hanya menghuni tiga pulau yaitu Kodingare, Kedatangan Suku
Bajo dan Suku Bugis di Kecamatan Pulau Sembilan adalah terutama dengan maksud pengejaran peluang ekonomi, yakni aktivitas penangkapan ikan dalam Kawasan Pulau Sembilan yang sangat kaya dengan sumber daya perikanan. Dalam perjalanan waktu yang tidak begitu panjang telah terjadi proses integrasi dan akulturasi diantara orang Bugis dan Bajo yang dimulai dalam batas-batas sepulau kemudian antar pulau. Dalam berbagai aspek kehidupan yang lebih luas seperti pola pemukiman, bahasa aliran keagamaan (Islam), Pendidikan, organisasi sosial atau kelompok kerja nelayan (punggawa-saw) dan terutama dalam hal pengetahuan dan teknologi pelayaran serta perikanan.

\section{B. Metode Penelitian}

1. Heuristik

Heuristik adalah pencarian serta pengumpulan sumber yang berkaitan dengan masalah atau objek yang ditulis dalam hal ini yang berkaitan dengan penelitian, dan pengumpulan data sekunder dari beberapa buku yang diperoh dari Perpustakaan Wilayah Provinsi Sulawesi Selatan, Perpustakaan Jurusan Pendidikan Sejarah UNM, Badan Pusat Statistik Kabupaten Sinjai, Perpustakaan Umum Universitas Negeri Makassar, dan Dinas Kelautan dan Perikanan Kabupaten Sinjai, kemudian diperkuat melalui kegiatan oservasi atau penelitian lapangan melalui tahap wawancara.

\section{Kritik}

Setelah pengumpulan data maka langkah selanjutnya yang dilakukan adalah krtitik sumber. menyaringnya secara kritik agar terjaring fakta yang menjadi pilihannya. 
Langkah-langkah inilah yang disebut kritik sumber (Sjamsuddin, Metodologi Sejarah, 2012)

\section{Interpretasi}

Fakta-fakta sejarah yang berhasil dikumpulkan belum banyak bercerita faktafakta tersebut harus disusun dan digabungkan sehingga membentuk cerita peristiwa sejarah proses ini disebut dengan interpretasi. (Madjid, Ilmu Sejarah Sebuah Pengantar, 2014)

\section{Historiografi}

Historiografi merupakan tahap akhir dari penelitian sejarah, setelah melalui fase heuristik, kritik, dan interpretasi.Pada tahap terakhir inilah penulisan sejarah dilakukan. Pada tahap ini fakta-fakta yang telah dirumuskan atau diinterpretasikan mengenai kehiduapan sosial ekonomi masyarakat nelayan Kecamatan Pulau Sembilan yang selanjutnya dirangkai dan disusun menjadi satu tulisan utuh

\section{Pembahasan}

1. Latar Belakang Kehidupan Sosial Ekonom Masyarakat Nelayan Kecamatan Pulau Sembilan

\section{a. Interaksi Masyarakat Antar Pulau Sembilan}

Proses interkasi yang terjadi pada masyarakat nelayan antar pulau selain hubungan kerja di laut adalah pada saat pembuatan rumah, perahu, kursi. Dimana masyarakat nelayan di satu pulau memiliki kecenderungan untuk memanfaatkan jasa tukang bangunan atau tukang kayu dari pulau lainnya. Interaksi masyarakat nelayan antar pulau juga terjadi dalam hal jual beli. Dimana masyarakat nelayan yang menjual barang campuran, bahan makanan bahkan ikan hasil tangkapan sering di pasarkan pada pulau yang bukan merupakan tempat tingglnya.

Hal lain yang sering menjadi penyebab terjadinya interaksi masyarakat antar pulau adalah ketika terjadi pernikahan antara masyarakat di satu pulau dengan pulau lainnya. Akan tetapi pada masa sebelum masuknya pengaruh modernisasi di Kecamatan Pulau Sembilan dalam bentuk mesin penggerak perahu, proses pernikahan yang dilangsungkan msayarakat pulau menyesuaikan dengan kondisi musim. Proses interaksi yang terjalin oleh masyarakat antar pulau mulai membaik seiring dengan masuknya pengaruh modernisasi, baik dari segi alat penggerak perahu hingga alat komunikasi yang semakin maju. Dengan adanya mesin penggerak perahu maka waktu tempuh dari satu pulau ke pulau lainnya menjadi lebih cepat.

Dari uraian diatas dapat dikatakan bahwa interaksi yang terjalin oleh masyarakat antar pulau dari masa ke masa dengan segala perubahan yang terjadi telah menjadi bagian penting dalam kehidupan sosial ekonomi masyarakat nelayan di Kecamatan Pulau Sembilan.

\section{b. Karakteristik Masyarakat Nelayan Pulau Sembilan}

Secara sosial karakteristik masyarakat nelayan selalu diidentikkan dengan masyarakat yang berwatak keras, memiliki rasa kekeluargaan yang tinggi serta pekerja keras. Hal ini disebabkan karena nelayan menghadapi sumberdaya yang tidak terkontrol yaitu hasil laut. Karakter seperti ini juga dimiliki oleh masyarakat nelayan di Kecamatan Pulau Sembilan. Dilain sisi nelayan di Kecamatan Pulau Sembilan juga termasuk kategori nelayan yang religius.

\section{c. Pola Hubungan Kerja Masyarakat Nelayan Pula Sembilan}

Berdasarkan perspektif Evers tersebut terlihat pula bahwa nelayan di Kecamatan Pulau Sembilan yang melaut pada saat itu masih bertujuan agar hasil tangkapannya dapat memenuhi kebutuhan sehari-hari dalam hal ini sebagai konsumsi pribadi. Walaupun terjadi proses transaksi atau penjualan tetapi itu tidak untuk dijadikan sebagai modal melainkan sebagai hasil penjualannya digunakan untuk membeli keperluan bahan pokok lainnya. 
PATTINGALLOANG

(C) Jurnal Pemikiran Pendidikan dan Penelitian Kesejarahan

Pola hubungan kerja masyarakat nelayan di Kecamatan Pulau Sembilan sebelum terjadinya proses modernisasi, masih bersifat kekeluargaan. Masyarakat nelayan Kecamatan Pulau Sembilan yaitu pada tahun 1960 pola penangkapan ikan secara umum masih bersifat tradisional.

Pada tahun 1970 masyarakat nelayan mulai mengenal teknologi modern dalam bentuk mesin penggerak perahu. Kehadiran teknologi modern dalam kegiatan penangkapan ikan telah mengubah pola hubungan kerja masyarakat nelayan. Jika sebelum mengenal teknologi modern nelayan lebih cenderung beroperasi secara sendirisendiri, maka setelah mengenal teknologi modern nelayan pun sudah mulai menggunakan pola hubungan kerja dalam bentuk punggawa-sawi. Pola hubungan kerja masyarakat nelayan dengan segala perubahannya dari tahun ke tahun telah menjadi bagian penting bagi kehidupan sosial ekonomi masyarakat nelayan di Kecamatan Pulau Sembilan.

\section{Kondisi Masyarkat Nelayan Pulau Sembilan Sebelum Modernisasi}

a. Konsep Modernisasi

Modernisasi tidak hanya mencakup perubahan secara fungsional atau sistem (teknik) dari cara- cara tradisional ke modern tetapi juga mengarah pada perubahan pola pikir manusia(Ahmadin, 2006; Rezky Sani, Ahmadin, \& Amirullah, 2018; Rifal \& Sunarti, 2018). Modernisasi tidak hanya sekedar terjadinya perubahan teknik dari tradisional ke cara-cara modern, tetapi juga meliputi perubahan pola pikir manusia Kondisi masyarakat nelayan Pulau Sembilan secara umum dapat dikatakan telah mengalami proses perubahan pada dua hal tersebut. Perubahan alat tangkap, perubahan jenis usaha penangakapan ikan dan pola hubungan kerja telah mengalami perubahan yang sangat signifikan. Proses perubahan pada usaha penagkapan ikan tersebut telah mengambil peranan penting dalam kehidupan sosial ekonomi msyarakat nelayan Kecamatan Pulau Sembilan.

\section{b. Jenis Alat tangkap dan Jangkauan Penangkapan}

Adapun jenis alat tangkap yang digunakan oleh nelayan sebelum terjadinya pemoderenan alat tangkap yaitu terdiri atas : Pancing, Panah, dan Bagang.

1) Pancing

Nelayan pengguna alat pancing ini dikelompokkan kedalam dua golongan yakni nelayan yang menggunakan perahu layar dan yang tidak menggunakan perahu. Nelayan yang menggunakan perahu untuk memancing ikan memiliki jangkauan wilayah yang sedikit lebih luas, dan dilengkapi dengan 3-5 mata pancing. Sedangkan nelayan yang tidak menggunakan perahu hanya melakukan penangkapan ikan terbatas di dekat pantai dengan satu mata pancing saja.

Waktu penangkapan ikan dengan menggunakan alat tangkap jenis pancing ini tidak terbatas, dengan kata lain dapat di gunakan pada waktu pagi, siang, sore, maupun malam hari.

2) Bubuh

Selain alat tangkap pancing, nelayan di Kecamatan Pulau Sembilan juga menggunakan alat tangkap yang disebut bubuh. Pemasangan bubuh di lakukan pada pagi hari dan pada sore hari nelayan akan datang kembali untuk memeriksa ikan yang terperangkap. Adapun cara pemasangan bubuh yaitu nelayan harus menyelam kedasar laut, kemudian bubuh diletakkkan di dekatdekat karang.

3) Panah

Jenis alat tangkap ini berbentuk seperti senapan yang terbuat dari kayu dengan tali karet untuk melontarkan panah yang terbuat dari besi tahan karat. Waktu pengoperasian alat ini juga tidak terbatas yakni bisa digunakan baik pagi, siang, sore, maupun malam hari. Hasil penangkapan dengan menggunakan alat tangkap ini juga di 
PATTINGALLOANG

(C) Jurnal Pemikiran Pendidikan dan Penelitian Kesejarahan

gunakan oleh para nelayan untuk memenuhi kebutuhan sehari-hari.

4) Bagang

Selain menggunakan alat tangkap jenis pancing, bubuh, dan panah nelayan di Kecamatan Pulau Sembilan juga menggunakan alat tangkap jenis bagang.. Sebelum masuknya pengaruh modernisasi nelayan di Kecamatan Pulau Sembilan hanya mengenal dua jenis bagang yaitu bagang tancap dan bagang rakit.

a) Bagang Tancap

Bahan baku untuk pembuatan bagang tancap adalah bambu. Adapun cara pengoperasian bagang tancap ini yaitu, Menjelang petang jaring diturunkan sekitar 1 meter dari permukaan laut. Kemudian saat malam hari oborpun dinyalakan, nelayan memantau dari atas tiang yang khusus dibuat untuk memantau dan menarik jaring.

b) Bagang Rakit

Alat tangkap ini menyerupi rakit yang dapat dipindah-pindah sesuai dengan keinginaan nelayan. Sehingga memungkinkan nelayan untuk menjangkau tempat yang memiliki banyak ikan. (Amirullah, M. Saleh Madjid, Junaeda S, 2018) Untuk mengoperasikan bagang rakit biasanya menggunakan 3- 5 orang yang bergantian untuk menjaga bagang. Pada saat ikan sudah berkumpul di dalam jaring, maka para nelayan mulai mengangkat jaring secara perlahan. Alat penerang yang digunakan oleh nelayan untuk memancing ikan masuk ke dalam jaring adalah lampu strongking. Nelayan di Kecamatan Pulau Sembilan menggunakan alat tangkap jenis bagang rakit ini hanya sekitar lima tahun yaitu dari tahun 1961-1965. Hal ini disebabkan karena bahan baku bagang hanya terbuat dari bambu sehingga tidak tahan lama dan mudah rapuh (Lampe, Berjuang Mengubah Nasib : Potret Dinamika Masyarakat Nelayan Pulau Sembilan Sinjai, 2010) c. Jaringan Pemasaran dan Sistem Bagi Hasil

1) Jaringan Pemasaran

Jaringan pemasaran ikan hasil tangkapan nelayan di Kecamatan Pulau Sembilan sebelum masuknya pengaruh modernisasi yaitu sekitar tahun 1960-an dapat dikatakan sangat sempit, Sehingga nelayan di Kecamatan Pulau Sembilan lebih sering menjual hasil tangkapannya kepada masyarakat yang mendiaami Pulau Sembilan itu sendiri (Wawancara, 2019).

2) Sistem Bagi Hasil

Sistem bagi hasil yang berlaku di Kecamatan Pulau Sembilan sebelum masuknya pengaruh modernisasi pada hakikatnya masih mengaut sistem kekeluargaan. Seorang nelayan yang memiliki alat tangkap dan juga perahu biasanya memanggil nelayan lainnya untuk membantu pekerjaannya, baik memancing ataupun memasang bubuh, setelah itu hasil tangkapan kemudian diberikan kepada nelayan yang membantu tersebut, yang jumlahnya menyesuaikan dengan banyak hasil tangkapan. Khusus untuk alat tangkap bagang biasanya hasil yang didapatkan oleh para nelayan yang ikut membantu nelayan pemilik bagang lebih banyak

\section{Kondisi Masyarakat Nelayan Kecamatan Pulau Sembilan Setelah Modernisasi}

a. Perkembangan Alat Tangkap dan Jangkauan Penangkapan

Pada fase 1970-an nelayan di Kecamatan Pulau Sembilan sudah mulai menggunakan mesin untuk menggerakkan perahu yang mereka gunakan untuk melakukan penangkapn ikan. Hal ini sesuai yang disampaikan nelayan yang bernama Ambo Rappe : "Saya yang pertama disini menggunakan mesin di perahu, saya membeli mesin itu dari penjualan ikan yang saya kumpulkan, merek mesin yang saya beli yaitu Honda 5 pk (Wawancara, 2019). Adapun usaha yang penagkapan ikan yang dilakukan nelayan yaitu, bagang perahu dan keramba. 
1) Bagang Perahu

Untuk membuat bagang perahu dibutuhkan biaya antara 25-30 juta rupiah, dengan ukuran bagang 10 meter persegi. Bagang perahu ini menggunakan layar untuk memindahkan bagang dari satu tempat ke tempat lainnya. Meskipun begitu layar ini bukanlah alat penggerak utama bagang perahu fungsinya hanya untuk membantu kerja perahu penarik (jolloro), agar bisa lebih cepat sampai ke tujuan. Untuk mengoperasikan sebuah bagang perahu dibutuhkan sekitar 7-9 orang. pada saat nelayan menggunakan bagang perahu pada saat itulah juga nelayan mengenal sebuah struktur kerja yang dinamakan punggawasawi.

2) Kerambah

Pada awal tahun 2001 nelayan mulai mengenal usaha keramba. Usaha keramba yang dilakukan nelayan di Kecamatan Pulau Sembilan tidak seperti keramba pada umumnya. Keramba yang ada di Kecamatan Pulau Sembilan hanya digunakan untuk menampung ikan hasil memancing agar tetap hidup. Jadi fungsi keramba bukanlah sebagai tempat budidaya melainkan sebagai tempat penampungan ikan yang berkualitas ekspor yang akan di jual dalam kondisi masih hidup. Untuk membuat keramba ini diperlukan modal sebesar RP 7.000.000. adapun bahan baku untuk pembuatan keramba yaitu, kayu, seng, jaring, dan drum. Kehadiran usaha keramba ini telah memberikan dampak yang sangat besar terhadap kondisi sosial ekonomi nelayan di Kecamatan Pulau Sembilan.

\section{Dari Nelayan Tangkap Menjadi Nelayan Budidaya}

Pada dasarnya nelayan di Kecamatan Pulau Sembilan telah melakukan aktivitas pengumpulan rumput laut sekitar tahun 1990-an. Namun masyarakat nelayan pada saat itu belum melakukan proses pembudidayaan. Nelayan hanya mengambil langsung rumput laut yang tumbuh liar di perairan yang dangkal. nelayan mulai berisiatif untuk membudidayakan rumput laut yaitu pada awal tahun 2003. Adapun jenis rumput laut yang dibudidayakan oleh masyarakat nelayan adalah filipina atau safari, hal ini sesuai dengan penuturan Hasbul yang mengatakan bahwa : "Jadi orang mengusaha agara' itu mulai tahun 2003 karena susah mi ikan gara-gara bom sama obat bius, terus gampang'i juga rumput laut dipasarkan bisa sampai Rp. 10.000 perkilo baru bagus ki disini pertumbuhannya rumput laut" (Wawancara, 2019) . Ada beberpa faktor yang menjadi penyebab masyarakat nelayan di Kecamatan Pulau Sembilan melakukan usaha budidaya rumput laut, yaitu :

a. Sulitnya memperoleh hasil tangkapan berupa ikan yang disebabkan oleh penggunaan alat tangkap terlarang sejenis bom dan obat bius.

b. Faktor pemasaran hasil yang mudah yang sangat jauh berbeda dengan kondisi pada tahun 1990-an ketika pertama kali nelayan mulai mengenal komoditi ini.

c. Harga rumput laut yang cukup menjanjikan di pasaran, dimana pada saat ini harga rumput laut kering sudah berkisar antara $\mathrm{Rp} 7.000$ sampai $\mathrm{Rp}$ 10.000 per kilo.

\section{Jaringan Pemasaran dan Sistem Bagi Hasil}

a. Jaringan Pemasaran

Hasil tangkapan yang diperoleh oleh nelayan bagang perahu semenjak mudahnya sarana transportasi mulai di pasarkan sampai ke TPI Lappa Kabupaten Sinjai dan TPI yang ada di kabupaten bulukumba. Khusus untuk pemasaran ikan hidup yang diperoleh nelayan melalui usaha keramba di pasarkan langsung kepada eksportir yang ada di makassar. Untuk pemasaran rumput laut langsung di pasarkan kepada eksportir yang ada di makassar.

b. Sistem Bagi Hasil

1) Sistem Bagi Hasil Pada Alat Tangkap Bagang Perahu

Sebelum pembagian hasil dilakukan terlebih dahulu dikeluarkan biaya operasional. Sisanya akan dibagi dua, 50\% 
PATTINGALLOANG

(C) Jurnal Pemikiran Pendidikan dan Penelitian Kesejarahan

untuk pemilik bagang (punggawa laut atau punggawa darat) dan $50 \%$ untuk punggawa laut beserta sawinya. Kemudian $50 \%$ untuk punggawa laut beserta sawinya dibagi lagi menjadi 3 bagian, 2 bagian untuk punggawa laut dan 1 bagian untuk sawi dibagi secara merata. Untuk punggawa darat yang hanya berperan dalam proses penjualan dan bukan pemilik bagang akan memperoleh komisi sebesar $10 \%$. (Amirullah, M. Saleh Madjid, Junaeda S, 2018) dan, (Wawancara, 2019).

2) Sistem Bagi Hasil Usaha Kerambah

Sistem bagi hasil pada usaha keramba yaitu, nelayan yang pergi menangkap ikan akan mendapatkan uang sesuai dengan banyaknya hasil tangkapannya, Sementara nelayan pemilik keramba akan mendapatkan keuntungan dari hasil penjualan terhadap pihak eksportir yang ada di Makassar. Dalam kegiatan sistem bagi hasil baik pemilik keramba maupun nelayan penangkap ikan saling diuntungkan

3) Sistem Bagi Hasil Budidaya Rumput Laut

Setelah tiba masa penjualan maka nelayan pemilik modal akan membeli hasil panen rumput laut yang telah dikeringkan dengan harga yang disesuaikan dengan harga rumput laut yang diberikan oleh pihak eksportir. Jika harga rumput laut berkisar pada angka $\mathrm{Rp} \mathrm{10.000/Kg} \mathrm{maka} \mathrm{nelayan}$ pemilik modal akan membeli rumput laut dari nelayan pekerja sebesar Rp.7.000/Kg. Sistem bagi hasil diupayakan seadil mungkin agar kerja sama antara nelayan pekerja dengan pemilik modal dapat berlangsung dalam jangka waktu yang lama. Adanya usaha rumput laut ini telah memberikan dampak yang sangat besar terhadap kondisi sosial ekonomi masyarakat nelayan (Wawancara, 2019)

\section{Kesimpulan \\ Kehidupan}

Kecamatan Pulau Sembilan sebelum masuknya pengaruh modernisasi, memiliki begitu banyak keterbatasan baik secara sosial maupun ekonomi. Setelah masuknya pengaruh modernisasi, kehidupan masyarakat nelayan di Kecamatan Pulau Sembilan mulai mengalami peralihan atau perubahan secara perlahan. Modernisasi atau motorisasi pada perahu mulai di kenal nelayan pada tahun 1970. Masuknya pengaruh modernisasi juga telah membuka jaringan pemasaran menjadi lebih luas. Hal ini telah mengubah pola pikir masyarakat nelayan di Kecamatan Pulau Sembilan untuk beralih dari nelayan tangkap menjadi nelayan pembudidaya rumput laut.

\section{Daftar Pustaka}

Buku Profil Kecamatan Pulau Sembilan Tahun . (2016). Kabupaten Sinjai.

(2019, November 1). Wawancara. (Salama, Interviewer)

(2019, November 2). Wawancara. (A. Rappe, Interviewer)

(2019, November 1). Wawancara. (Hasbul, Interviewer)

(2019, November 2). Wawancara. (H. Saide, Interviewer)

Abidin, Z. (Arsip Regening Van Oost Indonesia). 2003. Ujung Pandang: Badan Arsip dan Perpustakaan Daerah Provpnsi Sulawesi Selatan.

Ahmadin. (2017). Nelayan Tradisional dan Nelayan Modern. . Makassar : Rayhan Intermedia.

AKW, H. B. (2016). Lembah Walanae. Yogyakarta: Ombak.

Alimuddin, M. R. (2004). Mengapa Kita Belum Cinta Laut. Yogyakarta: Ombak.

Amirullah, M. Saleh Madjid, Junaeda S. (2018). The Existence Of Bagang Rambo In Gulf Of Bone (The Case Study Of Fisheman 
PATTINGALLOANG

(C) Jurnal Pemikiran Pendidikan dan Penelitian Kesejarahan

Community In Tarasu Village). In 1st International Cenference on Social Sciences (ICSS 2018). Atlantis Press (p. 134). Surabaya: Atlantis Press.

Arsip. (1950). Badan Arsip dan Perpustakaan Daerah Provinis Sulawesi Selatan Koleksi Arsip Pemerintahan Sulawesi Selatan. (1950-1960). Ujung Pandang.

Arsip. (1950). Badan Arsip dan Perpustakaan Daerah Provinis Sulawesi Selatan Koleksi Arsip Pemerintahan Sulawesi Selatan. (1950-1960) No Reg 209.

Arsip. (1950). Badan Arsip dan Perpustakaan Daerah Provinis Sulawesi Selatan Koleksi Arsip Pemerintahan Sulawesi Selatan. (1950-1960) No Reg 282.

Arsip. (n.d.). Arsip Dinas Kearsipan dan Kepustakaan Provinsi Sulawesi Selatan.

Arsip. (n.d.). Dengan berubahnya status daerah Soppeng sebagai daerah kabupaten dan diangkatnya Haji Andi Wana sebagai kepala daerah, maka dimulailah kegiatan penataan dan pembenahan administrasi pemerintahan daerah. Struktur organisasi pemerintah semasa Soppeng berstat.

Arsip. (n.d.). Dengan berubahnya status daerah Soppeng sebagai daerah kabupaten dan diangkatnya Haji Andi Wana sebagai kepala daerah, maka dimulailah kegiatan penataan dan pembenahan administrasi pemerintahan daerah. Struktur organisasi pemerintah semasa Soppeng berstat.

Arsip Dinas Kearsipan dan Kepustakaan Provinsu Sulawesi Selatan. (n.d.). Sulawesi Selatan.

Asrip Van Regering Van Oost Indoneise. (19641950). Pemerintah Negara Timur.
Badan Arsip. (n.d.). Badan Arsip dan Perpustakaan Daerah Provinis Sulawesi Selatan Koleksi Arsip Pemerintahan Sulawesi Selatan. Laporan Dari Acting Kepala Wanua Marioriwawo No Reg 1114.

BPS. (2018). Sinjai Dalam Angka 2018. Kabupaten Sinjai.

DEPDAGRI. (1992). Sejarah Perkembangan Pemerintahan di Suawesi Selatan. Ujung Pandang: DEPDAGRI Provinsi Sulawesi Selatan.

Hamid, A. R. (2008). Pengantar Ilmu Sejarah. Makassar: Rayhan Intermedia.

Hamid, A. R. (2015). Sejarah Maritim Indonesia. Yogyakarta: Ombak.

Lampe, M. (2010). Berjuang Mengubah Nasib : Potret Dinamika Masyarakat Nelayan Pulau Sembilan Sinjai. Makassar: Dian Istana.

Lampe, M. (2015). Punggawa Sawi, Nelayan Bugis Makassar dalam Analisis Relasi Internal dan Eksternal. Jurnal Masyarakat dan Budaya, 10.

Lembaran Negara RI. (1950). Lembaran Negara RI Nomor 28.

Lestari, R. E. (2008). Dualisme Pemerintahan Kerajaan Soppeng Pada Masa Penjajahan Kolonial Belanda. Makassar: Universitas Negeri Makassar.

Madjid, M. D. (2014). Ilmu Sejarah Sebuah Pengantar. Jakarta: Prenada Media Group.

Madjid, M. D. (2014). Ilmu Sejarah Sebuah Pengantar. Jakarta: Prenada Media Group.

Mantra, I. B. (2000). Demografi Umum. Yogyakarta: Pustaka Pelajar. 
PATTINGALLOANG

(C) Jurnal Pemikiran Pendidikan dan Penelitian Kesejarahan

Mattulada. (2015). Latoa: Suatu Lukisan Analitis Terhadap Antropologi Politik Orang Bugis. . Jakarta: Ombak.

Nonci. (2003). Sejarah Soppeng Zaman Prasejarah Sampapi Kemerdekaan. Makassar: CV. Aksara.

Nur, M. R. (20007). Rafiuddin. Makassar: Rumah Ide.

Nur, R. M. (2018). Lontara na Soppeng Dari Kerajaan Kembar Menuju Kabupaten. Makassar: Pustaka Refleksi.

Patunru, A. D. (2004). Bingkisan Patunru Sejarah Lokal Sulawesi Selatan. Makassar: Lephas.

Patunru, D. A. (1964). Sejarah Wajo Makassar. Makassar: Yayasan Kebudayaan Sulawesi Selatan.

Poelinggomang, L. E. (2004). Perubahan Politik dan Hubungan Kekuasaan Makassar 1906-1942 . Jakarta: Ombak.

Priyadi, S. (2012). Metode Penelitian Pendidikan Sejara. Yogyakarta: Ombak.
Ricklefs, M. (1991). Sejarah Indonesia Modern. Yogyakarta: Gajah Mada Universiti Press.

Salama. (2019, November 1). Wawancara. (Salama, Interviewer)

Sarita, P. (1938). Sejarah Perjuangan Angkatan 45 di Sulawesi Selatan. Ujung Pandang: PT. Gita Karya .

Sjamsuddin, H. (2012). Metodologi Sejarah. Yogyakarta: Ombak.

Sjamsuddin, H. (2012). Metodologi Sejarah. Yogyakarta: Ombak.

Surianingrat, B. (1981). Sejarah Pemerintaha di Indonesia Babak Hindia Belanda dan Jepang. Jakarta: Dewaruri Press.

Tamburaka, R. (1999). Pengantar Ilmu Sejarah, Teori Filsafat Sejarah, Sejarah Filsafat dan Iptek. Jakarta: Rineka Cipta. 